\section{Angina bullosa hemorrhagica: report of 11 cases}

\author{
Julieta Ruiz Beguerie, ${ }^{1}$ Silvina Gonzalez ${ }^{2}$ \\ 'Dermatology Department, Austral \\ University Hospital, Austral University, \\ Buenos Aires; '2Dermatology Department, \\ Stomatology Clinic, Hospital de Clinicas \\ Jose de San Martin, Buenos Aires, \\ Argentina
}

\section{Abstract}

Angina bullosa hemorrhagica is a rare and benign disorder, usually localized in the subepithelial layer of the oral, pharyngeal and esophageal mucosa. The lesions are characterized by their sudden onset. They appear as a painless, tense, dark red and blood-filled blister in the mouth that rapidly expand and rupture spontaneously in 24-48 hours. The underlying etiopathology remains ill defined, although it may be a multifactorial phenomenon including diabetes, and steroid inhalers. The condition is not attributable to blood dyscrasias, nor other vesicular-bullous disorders. In this study, eleven patients with such blisters are described. Physical examination of the patients revealed a single blister with hemorrhagic content localized in the oral mucosa. Biopsy of the lesions showed sub epithelial blisters with a mild infiltrate. In general practice, dermatologists could face a blood-filled bullous lesion of the oral mucosa. Recognition is, therefore, of great importance for dermatologists.

\section{Introduction}

In 1967 Badham was the first to introduce the term angina bullosa hemorrhagica $(\mathrm{ABH})$, a bullous disorder in which recurrent oral blood blisters appear in the absence of any identifiable systemic disorder, which heal uneventfully within 1 week. ${ }^{1,2}$ Other names that have been given to this disorder are benign hemorrhagic bullous stomatitis and recurrent or traumatic oral hemophlyctenosis. ${ }^{3,4}$ It can be one or more blood-filled blisters occurring at the same time and it is usually not painful, occurring in adults between 50-70 years old. There is no strong predilection for either male or female. They all heal spontaneously without scarring. ${ }^{4,5}$

\section{Case Report}

We studied 11 patients (4 males and 7 females) with $\mathrm{ABH}$. The mean age was 65 (range 46-86 years). All cases presented with a similar history of a single, localized blood-filled blister, which measured 4 to $7 \mathrm{~mm}$ in diameter (Figure 1). The blister spontaneously burst in 2-4 days, leaving a hemorrhagic content flow and erosion for 7 to 10 days. On examination, the Nikolsky sign was negative. Recurrences were seen in 2 patients. Eight of the 11 patients had the blister localized to the palate. The remaining three subjects had one lesion each localized to the lateral anterior third of the tongue, the gums and the jugal mucosa (Figure 2). Sixty four percent (7/11) had an associated systemic disease at the time of their initial visit. Four of these 7 individuals had arterial hypertension and 2 others had well-controlled NIDDM (non-insulin dependent DM) (Table 1). Trauma by sharp edges of adjacent teeth and metal crowns were identified as etiological factors in 4 cases. Lesions healed after removal of the metal crown and rounding of the sharp-edged teeth. Patients did not report a tendency to bleed at other sites. Laboratory evaluation failed to disclose any underlying illness. Platelet counts and coagulation tests were within normal limits in all patients.

The histopathology report in all cases reported a sub epithelial bulla filled with blood. Additionally there was an underlying mild to moderate nonspecific mononuclear inflammatory cell infiltrate, which was generally limited to the region of the lamina propria. Occasionally, neutrophils were seen. Performing a biopsy of an intact bulla is difficult because of the short duration in which the lesion stays intact (24-72 hours). Otherwise, a biopsy of a ruptured bulla only exhibits a nonspecific ulceration. Direct immunostaining for immunoglobulin G, A, or C3 are consistently noncontributory.

These patients were safely monitored with regular follow-ups due to minimal risk of complications.

\section{Discussion}

ABH presents clinically with blood-filled blisters that occur predominantly on the soft palate. They generally reach a diameter of $2 \pm 3$ $\mathrm{cm}^{6}$ They tend to burst spontaneously, leaving a ragged ulcer that heals without scarring. Approximately $30 \%$ of patients may have a recurrence. ${ }^{4}$

Occasionally patients may present clinically with hoarseness, or even blood-tinged sialorrhea. Following the rupture of the blister,
Correspondence: Julieta Ruiz Beguerie, Dermatology Department, Austral University Hospital, Av. Juan Domingo Perón 1500, Buenos Aires 1629 , Argentina.

Tel.: +54.1230.448.2000

E-mail: jruiz@cas.austral.edu.ar

Key words: angina bullosa haemorrhagica, bullous hemorrhagica, oral mucosa blisters.

Contributions: the authors contributed equally.

Conflict of interests: the authors declare no potential conflict of interests.

Received for publication: 2 January 2014.

Revision received: 6 February 2014.

Accepted for publication: 15 March 2014.

This work is licensed under a Creative Commons Attribution NonCommercial 3.0 License (CC BYNC 3.0).

(C) Copyright J.R.Beguerie and S.Gonzalez, 2014

Licensee PAGEPress, Italy

Dermatology Reports 2014; 6:5282

doi:10.4081/dr.2014.5282

painful ulcers may be present. The incidence is similar in both sexes (women, 52\%; men, 48\%). ${ }^{4}$ Laboratory evaluation, including CBC and coagulation profile, usually fails to disclose an underlying illness.

Its etiology remains obscure. $\mathrm{ABH}$ has been associated with a constitutional predisposition, such as loose cohesion between the epithelium and the corium of the mucosa, or a weak anchorage of mucosal vessels. This may predispose to sub-epithelial hemorrhages. As potential etiological factors, it has also been linked to arterial hypertension, diabetes mellitus and the long-term use of inhaled steroids. ${ }^{4,7,8}$ Grinspan et al., noted an association with diabetes mellitus, hyperglycemia, and/or a family history of diabetes in $44.4 \%$ of the 54 cases they studied with $\mathrm{ABH} .^{4}$

Stephenson published a large series of 30 patients, not finding a clear precipitating factor in $47 \%$ of the cases. ${ }^{6}$ There have been many precipitating factors described: trauma by a sharp cusp or edge of an adjacent tooth or metal crown, masticatory trauma, hot drinks, use of steroids, as well as dental or anesthetic procedures. ${ }^{6,9,10}$

The differential diagnosis is broad, including pemphigus, mucosal pemphigoid, cicatricial pemphigoid, epidermolysis bullosa acquisita, linear IgA dermatosis, toxidermia, bullous lichen planus, erythema multiforme, oral amyloidosis and fixed drug eruption. Haemorrhagic blisters can also appear in the setting of leukemia, vasculitis and other haematological and haemostatic disorders. ${ }^{11}$ 


\section{Case Report}

The histopathology reveals haemorrhagic subepithelial bullae, non-specific ulceration and a chronic inflammatory cell infiltrate in the lamina propria. ${ }^{6}$ In 1990, Edward was the first to document a case of an intradermal blister. This had not been described previously in the literature. ${ }^{9}$

Direct immunofluorescence is usually negative, but equivocal immunostaining for IgG and C3 has been previously reported. ${ }^{6,12}$

Although the risk of asphyxia is probably remote, palatal or pharyngeal blisters should be ruptured in order to prevent upper airway obstruction. In rare occasions, the size of the bulla and the free blood in the larynx requires intubation of the trachea by either fibreoptic endoscopy or direct laryngoscopy, or securing the airway by surgical tracheostomy. ${ }^{12}$

Treatment is symptomatic. Lesions can be treated successfully with topical steroids. Some lesions may heal after removal of the metal crown and rounding of the cusp preventing constant trauma. ${ }^{13-16}$

\section{Conclusions}

The aim of this paper is to report the clinical features and describe the management of 11 cases of $\mathrm{ABH}$. We feel it is extremely important to distinguish this benign disorder from other more serious blistering diseases of the oral mucosa with similar presenting features.

This disorder is likely under-reported. The lack of knowledge of this entity makes it very likely to be under-diagnosed. The recognition of the lesion is of great importance to avoid misdiagnosis. The examination of the oral mucosa and the skin, together with the medical history are the keys to diagnosis. The prognosis is good and this should also be stressed when advising patients. In general practice, the dermatologist can be confronted with a blood-filled bullous lesion of the oral mucosa. Recognition is, therefore, of great importance for dermatologists.

Table 1. Characteristics of the patients with angina bullosa haemorrhagica.

\begin{tabular}{lcccc} 
Patient & Age & Gender & Associated disease & Location \\
1 & 73 & F & HTN & Palate \\
2 & 86 & F & HTN & Palate \\
\hline 3 & 65 & M & DBT, MI & Palate \\
4 & 57 & M & - & Palate \\
\hline 5 & 46 & F & - & Palate \\
6 & 66 & F & Colon cancer & Palate \\
\hline 7 & 70 & F & Prostate cancer & Palate \\
8 & 63 & M & Alcoholism & Palate \\
\hline 9 & 48 & M & - & Gums \\
10 & 84 & F & HTN, breast cancer & Tongue \\
\hline 11 & 52 & F & - & Jugal mucosa \\
\hline
\end{tabular}

HTN, hypertension; MI, myocardial infarction; DBT, diabetes.

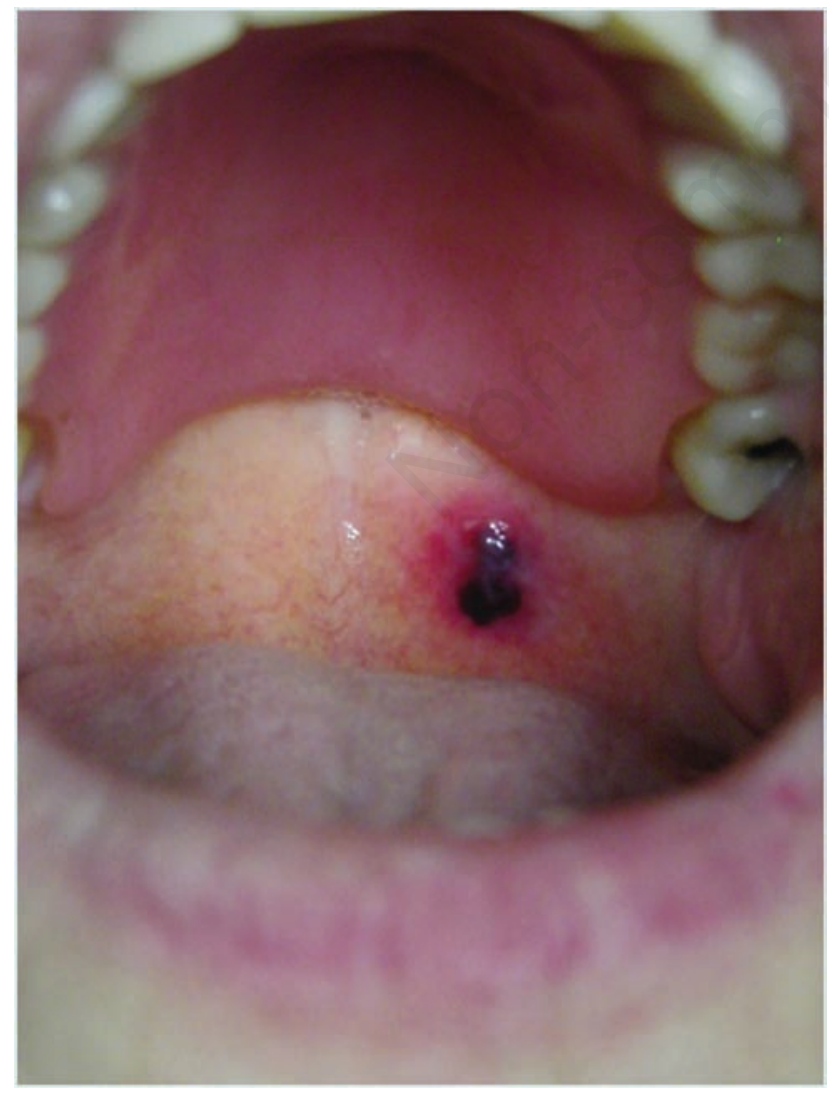

Figure 1. Single localized blood-filled blister of the oral mucosa (case 1).

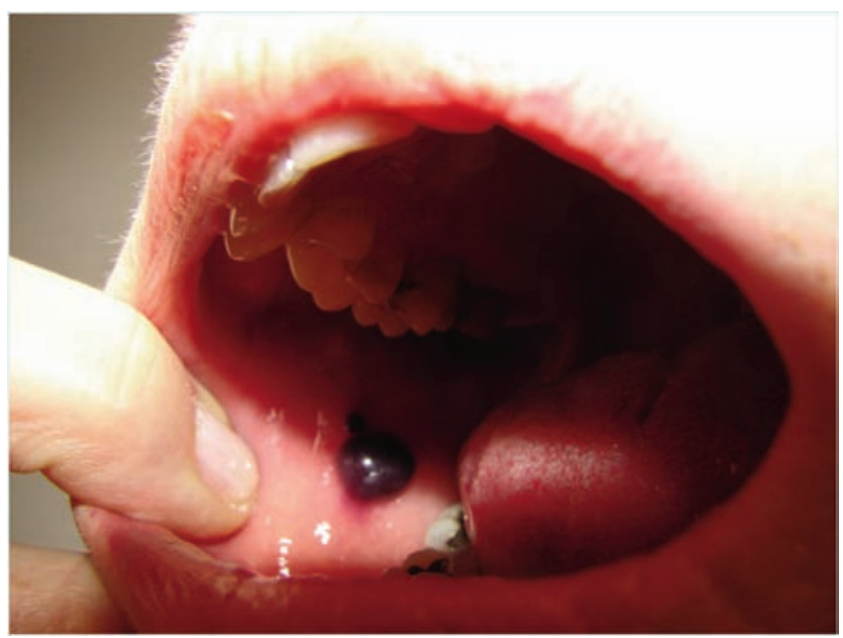

Figure 2. Blister in oral mucosa (other cases). 


\section{References}

1. Badham NJ. Blood blisters and oesophageal casts. J Laryngol Otol 1967;81:791-803.

2. Kirtschig G, Happle R. Stomatopompholyx haemorrhagica. J Am Acad Dermatol 1994;31:804-5.

3. Antoni-Bach N, Couilliet D, Garnier J, et al. Case for diagnosis. Benign hemorrhagic bullous stomatitis. Ann Dermatol Venereol 1999;126:525-6.

4. Grinspan D, Abulafia J, Lanfranchi H. Angina bullosa hemorrhagica. Int $\mathrm{J}$ Dermatol 1999;38:525-8.

5. Deblauwe BM, van der Waal I. Blood blisters of the oral mucosa (angina bullosa haemorrhagica). J Am Acad Dermatol 1994;31:341-4.
6. Stephenson P, Lamey PJ, Scully C, Prime SS. Angina bullosa haemorrhagica: clinical and laboratory features of 30 patients. Oral Surg Oral Med Oral Pathol 1987; 63:560-5.

7. Horie N, Kawano R, Inaba J, et al. Angina bullosa hemorrhagica of the soft palate: a clinical study of 16 cases. J Oral Sci 2008;50:33-6.

8. High AS, Main DMG. Angina bullosa haemorrhagica: a complication of long-term steroid inhaler use. Br Dent J 1988;165: 176-9.

9. Edwards S, Wilkinson JD, Wojnarowska F. Angina bullosa haemorrhagica: a report of three cases and review of the literature. Clin Exp Dermatol 1990;15:422-4.

10. Guillot B. Skin reactions to inhaled corticosteroids. Clinical aspects, incidence, avoidance and management. Am J Clin
Dermatol 2000;1:107-11.

11. Vaillant L, Fontès V. Bullous diseases of the oral mucosa. Rev Prat 2002;52:385-8.

12. Pahl C, Yarrow S, Steventon N, et al. Angina bullosa haemorrhagica presenting as acute upper airway obstruction. Br J Anaesth 2004;92:283-6.

13. Yip HK. Angina bullosa haemorrhagica: a case report and a concise review. Gen Dent 2004;52:162-4.

14. Petruzzi M. Angina bullosa haemorrhagica: a case report. J Biol Regul Homeost Agents 2009;23:125.

15. Giuliani M, Favia GF, Lajolo C, Miani CM. Angina bullosa haemorrhagica: presentation of eight new cases and a review of the literature. Oral Dis 2002;8:54-8.

16. de las Heras ME, Moreno R, Núñez M, et al. Angina bullosa hemorrhagica. J Dermatol 1996;23:507-9. 